\title{
Research on Rural Financial Problems based on Demand,Dilemma and Guarantee Countermeasures in China
}

\author{
Yanping Sun ${ }^{1, \mathrm{a}}$, Yongzhi Liu ${ }^{1, \mathrm{~b}}$ \\ ${ }^{1}$ Harbin Huade University, Harbin, China
}

\begin{abstract}
The rural financial service system gives full play to the functions of clearing payment and settlement, providing price information and incentive, accumulating capital and managing risks under the condition of market economy. However, it still faces the problems of financial ecological environment, financial supervision and internal structure of rural financial institutions. From the perspective of security and development, the development of rural finance must improve the diversified rural financial ecological subjects, improve the legal and credit environment of rural finance, perfect and innovate the rural financial system, and promote the development of rural intermediary service agencies. We must constantly update the rural financial supervision concept, innovate the rural financial supervision model, improve the rural financial supervision laws and regulations, and improve the rural financial supervision methods.
\end{abstract}

\section{INTRODUCTION}

Rural finance not only provides the convenience of investment and financing for micro-economic subjects, but also plays an important role in the economic development, national quality improvement and cultural promotion of the whole country. In fact, rural finance shows certain differences with different stages of rural economic development. Specifically, its functions are mainly reflected in the following aspects: Rural finance provides efficient and convenient payment and settlement methods in the form of checks, promissory notes, bills of exchange, credit cards, foreign exchange and entrusted collection, thus facilitating the exchange of goods and services among market participants; the function of providing information is mainly reflected in the form of interest rate, exchange rate and premium rate, analyzing and transmitting price information and forming reasonable price of rural financial assets rural economic activities are full of ubiquitous and inevitable uncertain factors and risks, mainly including agricultural production risks, agricultural and rural market risks, farmers' daily life risks, etc. Rural finance, especially insurance and guarantee, is an effective way to transfer and disperse the risks of financial activities.

\section{THE INHERENT DEMANDS OF RURAL FINANCIAL SERVICES}

\section{A. Farmers' demand for financial services}

The demand for rural financial services has not been limited to capital accumulation and credit, but has gradually shifted to the new demands of payment and settlement, information provision、 capital accumulation, incentive provision and risk management that are suitable for rural economic development. In order to meet the needs of economic growth, the financial services provided by the rural financial sector to promote financial development are also the inherent needs of the entire economic system and society. Farmers are the main participants of agricultural production and rural economy, and their behavioral characteristics of financial service demand also reflect diversity and hierarchy due to the different stages and regional differences of rural economic development. Financial institutions are willing to lend money to ordinary maintenance farmers because they value credit, have the traditional concept of "never talk about debt" and have low risk of capital demand. The eastern region of China has basically said goodbye to the traditional agricultural production mode. As the main body of agricultural industrial structure, farmers are mainly engaged in large-scale, market-oriented farming and breeding industry supplemented by agricultural production, they are typical market-oriented farmers. Such farmers have a great demand for loan funds and mainly use commercial credit to meet their demand for industrial and commercial loans. However, due to the 
lack of loan bearing mechanism, they often take the way of private lending and self-basic accumulation. In the context of increasing support from national agricultural policies and increasing agriculture-related loans, the scale of financial demand in China's rural areas keeps growing, as shown in Table 1.

\section{B. Rural enterprises' demand for financial services}

Both small and leading enterprises have strong financial needs. Due to the reasons of small scale, little accumulation, limited guarantee ability, poor stability of market operation and imperfect reputation, family-run enterprises need government guaranteed commercial credit and financial services provided by policy-based financial institutions to meet their capital needs of starting enterprise construction and expanding the market. Enterprises that have begun to take shape, especially rural commercial circulation enterprises, need financial services provided by policy-based financial institutions to meet their capital needs of resource development, product production, technological innovation, market expansion and competitiveness due to their large capital needs, low credit level, long production cycle and large market risks. Leading enterprises need the financial services to meet the capital needs of expanding markets, upgrading specialized technologies, upgrading infrastructure and engaging in diversified development.

Table 1 Agricultural loan of traditional financial institutions from 2015 to 2020

\begin{tabular}{|l|l|l|l|l|l|l|}
\hline & 2015 & 2016 & 2017 & 2018 & 2019 & 2020 \\
\hline $\begin{array}{l}\text { Total } \\
\text { agriculture- } \\
\text { related loans }\end{array}$ & 14.6 & 17.6 & 20.9 & 23.6 & 26.4 & 28.2 \\
\hline $\begin{array}{l}\text { Year-on-year } \\
\text { growth }\end{array}$ & 24.9 & 20.7 & 18.5 & 13.0 & 11.7 & 7.1 \\
\hline $\begin{array}{l}\text { Proportion of } \\
\text { total loans }\end{array}$ & 25.7 & 26.2 & 26.4 & 27.3 & 28.1 & 29 \\
\hline
\end{tabular}

Source: China Statistical Yearbook

\section{Local governments' demand for financial services}

With the development of economy and the progress of the society, as traffic, communication and public products, such as the main body of public health in the government requires a lot of funds for the rural regime stability, urbanization construction and the all-round development of the economy, in order to realize the inevitable rural compulsory education, rural public health, rural social security and rural science and technology promotion, source of funds in rural area is the key factors of economic growth, development, the number and quality of public goods supply. Therefore, local governments with strong capital needs should actively seek financing support from regional banks to gradually narrow the gap between supply and demand of funds and alleviate the shortage of funds in the region.

\section{THE DILEMMAS OF RURAL FINANCIAL DEVELOPMENT}

\section{A. The dilemmas of ecological environment in the development of rural finance in China}

The construction of credit investigation system is lagging behind and cannot meet the development requirements of rural market economy, the weak awareness of enterprise credit, the weak awareness of local government's performance and default of financial debts are the problems that often appear in the credit environment, which are very difficult and can be solved. It is difficult for rural enterprises and individuals to collect and evaluate credit information, which makes it difficult for rural financial institutions to carry out some work and establish a punishment mechanism for breaking trust. The lack of ideological understanding, there is no perfect legal system to adapt to the market economy to the rural economic development of the objective requirements; the judicial organs' business lacks standardization, debtors' obligations do not act, enterprises' organizational forms become dissimilar, suspended debts are difficult to sanction, etc., and agricultural credit creditor's rights lack legal protection the judicial organs lack effective means of law enforcement, with problems such as low law enforcement efficiency, high law enforcement costs, cumbersome law enforcement procedures, non-standard law enforcement and imperfect law enforcement supervision mechanism. System is an important factor for the construction of modern market economy, However, in the specific practice, there are some institutional problems in rural financial activities, such as the government's administrative intervention in the operation of financial institutions, the government's related departments applying for loans in disguised form, the imperfect intermediary institutions, the government's intervention in judicial execution, the lack of risk compensation mechanism and the urgent need to adjust the mechanism structure.

\section{B. The dilemmas of financial supervision in the development of rural finance in China}

At present, for the supervision mode and process, lack of enthusiasm and initiative, behavior deviation of rural financial institutions, lack of independence, lack of regulatory constraint mechanism, has not yet been established with pertinence, and adapt to the characteristics of the financial institutions, organizations, regulatory way, it is conceivable that it is difficult to fundamentally solve the complex causes a variety of financial risks. In addition to some problems existing in the above supervision, the lack of accounting system standards in the financial industry, serious moral hazard within the regulatory agencies and other reasons, there is a certain degree of distortion in regulatory information. At the same time, information distortion is closely related to negative supervision and too narrow supervision target. Effective financial supervision requires modernized 
supervision means, networked supervision system and perfect supervision mechanism. Rural financial institutions, especially those located in economically underdeveloped and remote areas; find it difficult to attract financial talents with professional knowledge and high quality. In addition, due to the lack of effective incentive mechanism, they often suffer from the loss of regulatory talent, impaired regulatory independence and authority.

Effective financial supervision requires modernized supervision means, networked supervision system and perfect supervision mechanism. Rural financial institutions, especially those located in economically underdeveloped and remote areas; find it difficult to attract financial talents with professional knowledge and high quality. In addition, due to the lack of effective incentive mechanism, they often suffer from the loss of regulatory talent, impaired regulatory independence and authority.

\section{The dilemmas of internal structure of the financial supervision in the development of rural finance in China}

At present, rural financial organization is a governmentoriented structure, although a series of rural financial reforms have been carried out under the leadership of the government, the function of resource allocation that adapts to the rapid development of rural finance is often ignored and the fundamental problems of rural finance cannot be solved. Therefore, on the one hand, the rural financial demand cannot be fully met due to the insufficient supply of financial institutions; second, the existing financial institutions are unable to meet the diversified needs of rural finance due to the lack of necessary market competition and innovation impetus.

\section{GUARANTEE COUNTERMEASURES OF RURAL FINANCIAL DEVELOPMENT IN CHINA}

\section{A. Strengthening the construction of rural financial ecological environment}

Actively build a financial system composed of commercial finance, policy-based finance, community mutual assistance finance and cooperative finance based on the multi-level demands of rural economic development, and form a good atmosphere of cooperation and competition based on governments at all levels giving full play to their respective functions; Actively carry out the management mechanism reform and management mechanism construction of financial institutions based on constraint and incentive mechanism, and constantly enhance their own development and coordination ability.

Some defects and deficiencies of the existing financial law, therefore, the local government needs to fully consider the current situation of the rural economic development and financial needs of reality, in the process of legislation and enforcement, try to solve the absence of law in financial activities, management confusion, execution, such as low efficiency and poor enforcement effect problem, which not only can promote the improvement of the regional financial legal environment, avoid the interests of the local shelter. The main tasks are as follows: First, make timely adjustments according to the different stages of economic development in different regions and rural areas as well as the conditions of agricultural production and operation, so as to ensure that the business operations of policy banks and the supervision of regulatory departments have laws to follow; the second is to constantly improve the existing rural financial legislation, improve the rural financial creditors to protect their property "Bankruptcy law", improve the "security law" to avoid creditor's rights risk; third, we will continue to improve and adjust the relevant legal systems. We will improve the management system of intermediary agencies, accelerate the establishment of a credit system, improve the administrative system that standardizes administrative acts, and improve relevant systems that enhance the efficiency of judicial enforcement.

Improve diversified and orderly competitive rural financial ecological subjects. Build actively a financial system composed of commercial finance, policy-based finance, community mutual assistance finance and cooperative finance based on the multi-level demands of rural economic development, and form a good atmosphere of cooperation and competition based on governments at all levels giving full play to their respective functions. Actively develop rural intermediary service agencies. To change the unitary tendency of financial institutions to corporate credit rating, to form an open credit data collection and inquiry system, and to keep the credit data collection and exchange relationship between financial institutions close; to use effective economic incentive means and necessary legal system to guarantee the professional service level and quality of intermediary services, we should not only actively absorb and learn from foreign advanced experience and the introduction of industry standards and norms, but also strengthen the professional training and moral construction of employees.

\section{B. Innovating the supervision model of rural financial}

Unified supervision, lead supervision and umbrella supervision are several commonly used supervision modes at present. There is no universally applicable financial supervision mode. Each supervision mode has its own applicability, and different regions and levels and stages of economic development should adopt different supervision modes, which cannot be simplified. At present, China should give full play to the role of CBRC in the selection and innovation of financial supervision mode, and effectively achieve the financial supervision goal of "maintaining the legal and stable operation of the financial industry". 


\section{The establishment of market-oriented government to transform the government- oriented rural financial organization structure}

We will establish a coordination mechanism for financial stability and strengthen efforts to build a credible government. In practice, the normal development of rural finance will be affected if the government fails to fully solve the market failure or effectively promote the reform of financial system and mechanism. The government should constantly learn from the technology and experience of foreign financial supervision and give full play to the functions of institutional innovation, mechanism innovation and technological innovation. Therefore, in the process of promoting the development of rural finance, the government should constantly introduce market competition and advanced management system to solve the financial market failure. At the same time, we should make active use of market forces and transform government functions by introducing market mechanism and entrepreneurship into government management, so as to improve government management level and service level.

\section{CONCLUSION}

The construction of the rural financial system, the reform of the mechanism and the adjustment of the structure is a long-term process which cannot be accomplished overnight. Therefore, it is necessary to introduce the market mechanism, change the role of the government and strengthen the macro-function of the government. The government should improve actively the economic, legal, credit environment, and actively innovate in the ways, means and modes of supervision to build an ecological environment for rural financial development; we must innovate from the top. We should give full play to the positive role of rural finance in the adjustment of rural economic structure, the production and consumption of rural households, the increase of rural income and the sustainable development of agriculture.

\section{REFERENCES}

1. Chen Dan. Research on the Construction of Rural Financial Supervision System under the Background of Rural Revitalization Strategy [J]. Agricultural Economics, 2020 (4)J. Clerk Maxwell, A Treatise on Electricity and Magnetism, 3rd ed., vol. 2. Oxford: Clarendon, 1892, pp.68-73.

2. Wang Yiwei. Research on financial Support for Rural Economic Development and Countermeasures [J]. China Market, $2020(4) \mathrm{K}$ Elissa, "Title of paper if known," unpublished.

3. Xiao Xingyu. Financial Restraint and Lifting in rural Economic Development [J]. Rural Economy and Science and Technology, 2019 (12)

4. Zhao Tianrong. Theoretical necessity and Practical restriction of Rural financial Supervision -- Based on the investigation of the new pattern of rural finance in China [J]. Economic Issues, 2014, (4)

5. Chen Lixian. Research on Rural Financial Issues from the Perspective of Targeted Poverty Alleviation [J]. Rural Economics and Technology, 2019 (12) 